\title{
Development of a normal tissue complication probability (NTCP) model for radiation-induced hypothyroidism in nasopharyngeal carcinoma patients
}

Ren Luo ${ }^{1,2}$, Vincent W. C. Wu ${ }^{3}$, Binghui He ${ }^{1}$, Xiaoying Gao ${ }^{1}$, Zhenxi Xu' ${ }^{1}$, Dandan Wang ${ }^{1}$, Zhining Yang ${ }^{1}$, Mei Li ${ }^{1 *}$ and Zhixiong $\operatorname{Lin}^{1 *}$

\begin{abstract}
Background: The objectives of this study were to build a normal tissue complication probability (NTCP) model of radiation-induced hypothyroidism (RHT) for nasopharyngeal carcinoma (NPC) patients and to compare it with other four published NTCP models to evaluate its efficacy.

Methods: Medical notes of 174 NPC patients after radiotherapy were reviewed. Biochemical hypothyroidism was defined as an elevated level of serum thyroid-stimulating hormone (TSH) value with a normal or decreased level of serum free thyroxine (fT4) after radiotherapy. Logistic regression with leave-one-out cross-validation was performed to establish the NTCP model. Model performance was evaluated and compared by the area under the receiver operating characteristic curve (AUC) in our NPC cohort.
\end{abstract}

Results: With a median follow-up of 24 months, 39 (22.4\%) patients developed biochemical hypothyroidism. Gender, chemotherapy, the percentage thyroid volume receiving more than $50 \mathrm{~Gy}\left(V_{50}\right)$, and the maximum dose of the pituitary $\left(P_{\max }\right)$ were identified as the most predictive factors for RHT. A NTCP model based on these four parameters were developed. The model comparison was made in our NPC cohort and our NTCP model performed better in RHT prediction than the other four models.

Conclusions: This study developed a four-variable NTCP model for biochemical hypothyroidism in NPC patients post-radiotherapy. Our NTCP model for RHT presents a high prediction capability.

Trial registration: This is a retrospective study without registration.

Keywords: Radiation-induced hypothyroidism, Normal tissue complication probability, Nasopharyngeal carcinoma, Radiotherapy, Late complication

\section{Background}

Radiation-induced hypothyroidism (RHT) is one of the common late complications in patients receiving radiotherapy to the neck region, which could be subclinical or clinical. The subclinical hypothyroidism (HT), in the presence of an elevated serum thyroid-stimulating hormone (TSH) concentration and normal serum free thyroxine (fT4) and/or serum free triiodothyronine (fT3)

\footnotetext{
*Correspondence: limei00182@139.com; zxlin5@qq.com

${ }^{1}$ Department of Radiation Oncology, Cancer Hospital of Shantou University Medical College, 7 Raoping Road, Shantou 515000, Guangdong, China Full list of author information is available at the end of the article
}

concentration, can only be diagnosed by a laboratory test. The clinical HT which is characterized by an elevated TSH concentration and decreased fT4 and/or fT3 concentration is more overt with fatigue, cold intolerance, weight gain, constipation and dry skin as the major clinical manifestations. The incidence of radiationinduced clinical HT is $6-20 \%$ of head and neck cancer patients, while the incidence of subclinical HT is higher, ranging from 24 to $50 \%$ [1].

Nasopharyngeal carcinoma (NPC) is an epidemic cancer in Southern China. Irradiation to bilateral necks is a regular practice since the disease presents with a high

(c) The Author(s). 2018 Open Access This article is distributed under the terms of the Creative Commons Attribution 4.0 International License (http://creativecommons.org/licenses/by/4.0/), which permits unrestricted use, distribution, and reproduction in any medium, provided you give appropriate credit to the original author(s) and the source, provide a link to the Creative Commons license, and indicate if changes were made. The Creative Commons Public Domain Dedication waiver (http://creativecommons.org/publicdomain/zero/1.0/) applies to the data made available in this article, unless otherwise stated. 
incidence of neck lymphadenopathy of over 75\% [2], resulted in unavoidable irradiation with relatively high dose to part of the thyroid gland. Previous studies have reported the relatively high incidence of RHT $(22.1 \%$ to $33.7 \%$ ) in post-radiotherapy NPC patients [3-6]. Since the life span expectation of NPC patients has remarkably improved in the last decade due to the emerging of effective chemotherapy and advanced radiotherapy techniques [7], the demand for reducing the radiationinduced side effects including RHT has been increasing.

Clinical characteristics included gender $[3,8,9]$, age $[3,10-12]$, neck surgery $[13]$ and early $\mathrm{T}$ stage $[3,11]$ were considered as risk factors of RHT. Nowadays, dose-volume data is available by retrieving from the commercial treatment planning system and the parameters such as the thyroid minimum dose $\left(D_{\text {min }}\right)$, the thyroid mean dose $\left(D_{\text {mean }}\right)$, and the percentage of thyroid volume receiving more than $30,40,45,50$ Gy $[4,10-12,14-20]$ were identified to be dosimetric predictors for RHT. Therefore, establishing a normal tissue complication probability (NTCP) model based on both clinical and dose-volume factors may offer an effective method of predicting RHT [21]. Two NTCP models [16] for RHT based on Hodgkin's lymphoma patients have been reported. Another two NTCP models based on the thyroid mean dose and thyroid volume have also been built for head and neck cancer patients excluding NPC [14, 17].

Unlike non-NPC cases, the dose to thyroid and pituitary glands are relatively high in most NPC patients. Therefore, it remains doubtful whether the NTCP models $[14,16,17]$ for RHT based on non-NPC patients are applicable for NPC patients. We conducted this study to establish a NTCP model for RHT in NPC survivors and evaluated its performance by comparing it with four existing models.

\section{Methods}

The detail information of patient eligibility, radiation therapy, chemotherapy regimen, and thyroid function evaluation was also described in our previous publications $[4,22]$.

\section{Patient eligibility}

Patients' records from an ongoing prospective study [4] of post-radiotherapy thyroid changes in NPC patients were reviewed. Patients with normal baseline thyroid hormone levels (normal TSH, fT3, and fT4) before radiotherapy, without previous and present thyroid dysfunction, and without receiving electron boost or neck surgery to residual lymph nodes were eligible. One hundred and seventy-four newly diagnosed NPC patients in Cancer Hospital of Shantou University Medical College, which were recruited from December 2007 to February 2015, met the criteria and were included in this retrospective study. They were all re-staged using the 7th edition of American Joint Committee on Cancer (AJCC) staging system. This study was approved by our center's institutional review board.

\section{Radiation therapy and dosimetric analysis}

For all patients, CT scans (CT scanner: Philips Brilliance CT Big Bore Oncology Configuration, Cleveland, OH) were performed in the supine position with intravenous contrast using a $3 \mathrm{~mm}$ slice thickness from the head to $2 \mathrm{~cm}$ below the sternoclavicular joint. The CT images were then transferred to Pinnacle 7.6c treatment planning system (TPS) (Pinnacle ${ }^{3}$, Philips, Eindhoven, The Netherlands), on which the target volumes and the organs at risk (OARs) including thyroid and pituitary glands were contoured manually.

In NPC radiotherapy planning, the gross tumor volume (GTV) included the primary disease (GTVnx) and the lymph nodes (GTVnd). The clinical target volume of the nasopharynx (CTVnx) included the anatomic areas at risk of microscopic invasion [23]. The CTV of the lymph nodes (CTVnd) included lymph nodes at II to V levels. High-risk CTV (CTV1) indicated soft tissue adjacent to GTV and involved lymphatic drainage regions. Low-risk CTV (CTV2) included the bilateral II, III, and VA for N0 cases and ipsilateral IV, VB for the cases with levels II and/or III involved The planning target volume (PTV) was established by adding $3-5 \mathrm{~mm}$ to the CTV.

Dose prescription to PTVs was stated as follows: 70Gy to the PTVnx in 2.0 Gy per fraction for 3-dimensional conformal radiotherapy (3D-CRT), or 2.12 to 2.33 Gy per fraction for intensity-modulated radiotherapy (IMRT); 66 Gy to the PTVnd; 60 Gy to the PTV1 of high-risk CTV1 and 54 Gy to the PTV2 of low-risk CTV2. The dose constraints of normal tissue: the maximum dose $\left(D_{\max }\right)$ of the brainstem, optic nerves, optic chiasm, spinal cord, lens was $54 \mathrm{~Gy}, 54 \mathrm{~Gy}, 54 \mathrm{~Gy}$, $45 \mathrm{~Gy}$, and $5 \mathrm{~Gy}$, respectively; $\mathrm{D}_{\text {mean }}$ of parotid gland, oral cavity and larynx was 35 Gy, 38Gy and 38 Gy, respectively. No specific dose constraints were performed to constrictors, pituitary and thyroid glands.

No patients underwent re-CT and re-planning during radiotherapy. The dosimetric data was generated from TPS, including $D_{\min }, D_{\max }$, and $D_{\text {mean }}$ to thyroid; the maximum and mean dose to pituitary $\left(\mathrm{P}_{\max }\right.$ and $\left.\mathrm{P}_{\text {mean }}\right)$; the percentage of thyroid volume receiving more than $\mathrm{X}$ Gy $\left(V_{x}\right)$ in step of 5 Gy from 10 to 60 Gy; the absolute volume receiving more than $30 \mathrm{~Gy}\left(\mathrm{~V}_{30} \mathrm{cc}\right)$ of thyroid and the absolute thyroid volume.

\section{Chemotherapy}

The neoadjuvant chemotherapy regimen was one cycle of docetaxel $75 \mathrm{mg} \mathrm{m}^{-2}$ on Day 1 and two cycles of cisplatin $75 \mathrm{mg} \mathrm{m}^{-2}$ on Days 1 and 22. Concurrent 
chemotherapy consisted of cisplatin $75 \mathrm{mg} \mathrm{m}^{-2}$ on Day 1 and $96 \mathrm{~h}$ of continuous infusion fluorouracil $750 \mathrm{mg} \mathrm{m}^{-2}$ /day every 3 weeks for two cycles. Adjuvant chemotherapy regimen was the same as the regiment of concurrent chemotherapy, but it was administered every 3 weeks for two cycles post-radiotherapy.

\section{Thyroid function evaluation}

Thyroid function included TSH, fT3, and fT4 levels were evaluated pre-radiotherapy and at each follow-up visit. The electrochemiluminescence method by Elecsys 2010 analyzer (Hitachi High Technology Corporation, Tokyo, Japan) was used, with the reference ranges of $0.27-4.20$ $\mu \mathrm{IU} / \mathrm{mL}, \quad 3.1-6.8 \mathrm{pmol} / \mathrm{L}$, and $12.0-22.0 \mathrm{pmol} / \mathrm{L}$, respectively. The reproducibility of the three thyroid hormones tests was acceptable, and their coefficient variations ranged between $1.3 \%$ and $1.5 \%$. After radiotherapy, thyroid hormones tests were performed every 3 months during the first year, every 6 months in the second to the fifth year and annually after that. Biochemical HT is TSH value $>4.20 \mu \mathrm{IU} / \mathrm{mL}$ with the low or normal level of fT4. Patients whose fT3 and fT4 were at low levels and with low or normal TSH level, would be diagnosed as central HT.

\section{Statistical analysis}

The endpoint of this study was biochemical HT. In NTCP pre-modeling process, Spearman's rank correlation coefficients were calculated to access the correlation between different variables, and the correlation between different variables and the biochemical HT using SPSS 21. 0 software (SPSS, Inc., Chicago, IL, USA). If the Spearman's rank correlation coefficient was greater than 0.85 between two variables, the one with the lower correlation with biochemical HT would be excluded from NTCP modeling to avoid model overfitting [16]. Univariate logistic regression analyses for both clinical and dose-volume factors were also applied using SPSS 21.0 software. The NTCP modeling was performed by an open-source tool (Dose Response Explorer System [21]) and based on the multivariable logistic regression formula:

$$
\mathrm{NTCP}=\left(1+\mathrm{e}^{-\mathrm{S}}\right)^{-1}
$$

where $S=\beta_{0}+\beta_{1} x_{1}+\beta_{1} x_{1}+\ldots+\beta_{m} x_{m} . x_{1}, x_{2} . . . x_{m}$ are different input parameters, and $\beta_{0}, \beta_{1} \ldots \beta_{\mathrm{m}}$ are the logistic regression coefficients of corresponding input parameters.

In modeling process, the variable chemotherapy was coded 0 (not receiving chemotherapy) and 1 (receiving chemotherapy); the variable gender was coded 1 (female) and 0 (male). First, the optimal model order was estimated by leave-one-out cross-validation (2000 samples). Second, the model parameters were estimated by multivariate logistic regression analysis with the forward selection with 1000 bootstraps. The goodness-of-fit of our NTCP model was evaluated by the Hosmer-Lemeshow test and visualized in an octile plot. In octile plot,

Table 1 Five normal tissue complication probability (NTCP) models from four published and present study

\begin{tabular}{|c|c|c|c|c|c|}
\hline NTCP model & $b$ & constant & OR & $95 \% \mathrm{Cl}$ & AUC \\
\hline Boomsma et al. & & 0.011 & & & 0.85 (95\% Cl: 0.78-0.92) \\
\hline$D_{\text {mean }}$ & 0.062 & & $1.064 / \mathrm{Gy}$ & $1.029-1.101$ & \\
\hline Thyroid volume & -0.19 & & $0.826 / \mathrm{cm}^{3}$ & $0.740-0.921$ & \\
\hline Cella et al. model 1 & & -1.83 & & & 0.865 (95\% Cl: $0.793-0.945)$ \\
\hline V30\% & 0.038 & & 1.039 & $1.019-1.059$ & \\
\hline Gender & -2.32 & & 0.098 & $0.019-0.500$ & \\
\hline Cella et al. model 2 & & 1.94 & & & 0.874 (95\% Cl: $0.750-0.951)$ \\
\hline V30 cc & 0.26 & & 1.297 & $1.087-1.547$ & \\
\hline Gender & -2.21 & & 0.110 & $0.021-0.580$ & \\
\hline Thyroid volume & -0.27 & & 0.763 & $0.615-0.947$ & \\
\hline Rønjom et al. & & -2.019 & & & NA \\
\hline$D_{\text {mean }}$ & 0.0821 & & 1.12/Gy & $1.07-1.20$ & \\
\hline Thyroid volume & -0.189 & & $0.75 / \mathrm{cm}^{3}$ & $0.64-0.85$ & \\
\hline Luo et al. & & -2.695 & & & $0.793(95 \%$ Cl: $0.725-0.851)$ \\
\hline$V_{50}$ & 0.050 & & 1.051 & $1.027-1.076$ & \\
\hline$P_{\max }$ & -0.026 & & 0.974 & $0.956-0.993$ & \\
\hline Gender & 1.280 & & 3.598 & $1.461-8.865$ & \\
\hline Chemotherapy & 2.902 & & 18.213 & $1.920-172.766$ & \\
\hline
\end{tabular}

Abbreviation: $O R$ odds ratio, $C l$ confidence interval, $A U C$ the area under the receiver operating characteristic curve, $N A$ not available in original article 
Table 2 Patient characteristics and the correlation between clinical factors and RHT

\begin{tabular}{|c|c|c|c|c|c|}
\hline \multirow[b]{2}{*}{ Variables } & \multirow[b]{2}{*}{$n(\%)$} & \multirow{2}{*}{$\begin{array}{l}\text { Univariate } \\
p \text { value }\end{array}$} & \multicolumn{3}{|c|}{ Multivariate } \\
\hline & & & $\overline{p \text { value }}$ & OR & $95 \% \mathrm{Cl}$ \\
\hline Numbers & 174 & & & & \\
\hline Gender & & 0.005 & 0.005 & 3.598 & $1.461-8.865$ \\
\hline Female & 45 (25.9) & & & & \\
\hline Male & $129(74.1)$ & & & & \\
\hline Age (years) & & 0.066 & & & \\
\hline Median & 49.5 & & & & \\
\hline Range & $16-69$ & & & & \\
\hline T stage & & 0.170 & & & \\
\hline $1-2$ & $64(36.8)$ & & & & \\
\hline $3-4$ & $110(63.2)$ & & & & \\
\hline N stage & & 0.329 & & & \\
\hline 0 & $16(9.2)$ & & & & \\
\hline $1-3$ & $158(90.8)$ & & & & \\
\hline Stage & & 0.174 & & & \\
\hline$|-| \mid$ & $20(11.5)$ & & & & \\
\hline III-IV & $154(88.5)$ & & & & \\
\hline Technique & & 0.393 & & & \\
\hline 3D-CRT & $32(18.4)$ & & & & \\
\hline IMRT & $142(81.6)$ & & & & \\
\hline Chemotherapy & & 0.091 & 0.011 & 18.213 & $1.920-172.766$ \\
\hline No & 19 (10.9) & & & & \\
\hline Yes & 155 (89.1) & & & & \\
\hline
\end{tabular}

Abbreviation: $O R$ odds ratio, $\mathrm{Cl}$ confidence interval

patients were uniformly binned into 8 groups based on the predicted risk of biochemical HT by our model.

The regression coefficients of four existing logistic regression based NTCP models: Boomsma et al., Cella model 1 et al., Cella model 2 et al., and Rønjom et al.

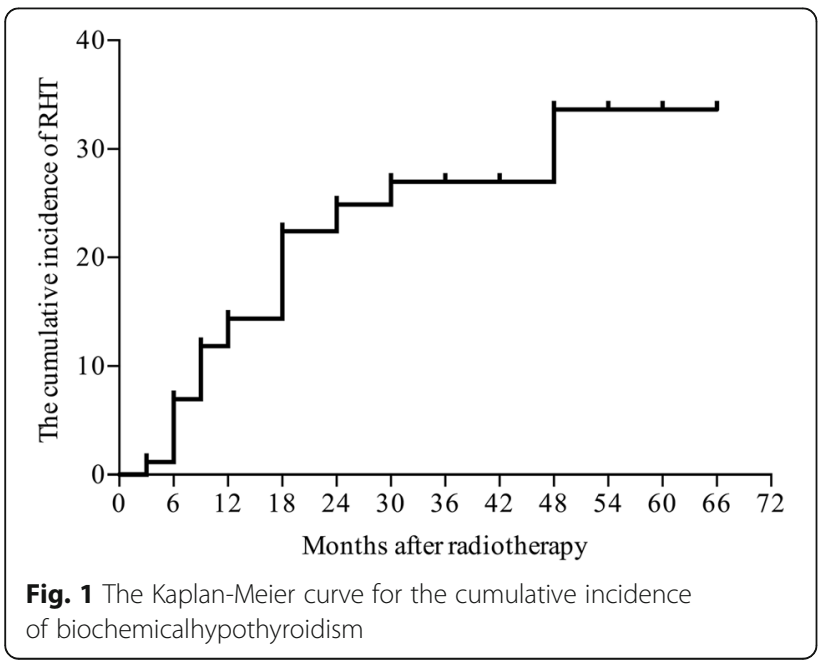

Table 3 Univariate and multivariate analysis of dosimetric variables

\begin{tabular}{|c|c|c|c|c|c|c|}
\hline \multirow[b]{2}{*}{ Variables } & \multirow[b]{2}{*}{ mean } & \multirow[b]{2}{*}{ SD } & \multirow{2}{*}{$\begin{array}{l}\text { Univariate } \\
p \text { value }\end{array}$} & \multicolumn{3}{|c|}{ Multivariate } \\
\hline & & & & $p$ value & OR & $95 \% \mathrm{Cl}$ \\
\hline Volume (cc) & 17.324 & 8.403 & 0.703 & & & \\
\hline$D_{\min }(G y)$ & 19.579 & 12.768 & 0.016 & & & \\
\hline$D_{\text {mean }}(G y)$ & 42.417 & 10.145 & 0.001 & & & \\
\hline$D_{\max }(G y)$ & 65.500 & 5.819 & 0.536 & & & \\
\hline \multicolumn{7}{|l|}{$V_{x}(\%)$} \\
\hline$V_{10}$ & 91.111 & 16.341 & 0.124 & & & \\
\hline$V_{15}$ & 88.863 & 19.032 & 0.128 & & & \\
\hline$V_{20}$ & 86.660 & 21.072 & 0.093 & & & \\
\hline$V_{25}$ & 84.135 & 23.041 & 0.070 & & & \\
\hline$V_{30}$ & 80.583 & 25.409 & 0.038 & & & \\
\hline$V_{35}$ & 74.270 & 25.425 & 0.011 & & & \\
\hline$V_{40}$ & 62.308 & 23.050 & 0.001 & & & \\
\hline$V_{45}$ & 50.496 & 21.220 & 0.000 & & & \\
\hline$V_{50}$ & 38.915 & 19.477 & 0.000 & 0.000 & 1.051 & $1.027-1.076$ \\
\hline$V_{55}$ & 24.598 & 16.243 & 0.000 & & & \\
\hline$V_{60}$ & 12.111 & 12.856 & 0.006 & & & \\
\hline $\mathrm{V}_{30} \mathrm{CC}$ & 14.044 & 8.133 & 0.730 & & & \\
\hline$P_{\text {mean }}(G y)$ & 30.366 & 22.712 & 0.072 & & & \\
\hline$P_{\max }(G y)$ & 37.856 & 23.719 & 0.054 & 0.007 & 0.974 & $0.956-0.993$ \\
\hline
\end{tabular}

$[14,16,17]$ were given in Table 1 . Model performance was evaluated by the area under the receiver operating characteristic curves (AUC). Firstly, a comparison of AUCs of each model in its own cohort was performed using z-test. Secondly, the AUCs of these five models in our NPC cohort were calculated and compared using the method suggested by Delong et al. [24] using MedCalc 11.4.2.0 (MedCalc, Mariakerke, Belgium). The comparing method for ROC by DeLong et al. is a nonparametric method that does not require the assumption of normality. For this reason, this method has become the most widely used one in practice. A $p$-value of $<0.05$ was considered statistically significant.

\section{Results}

One hundred and seventy-four patients (129 males and 45 females) with a median age of 49.5 (range, 16 to 69) years old were included in this study. Thirty-two (18.4\%) patients were treated with 3D-CRT while the other 142 (81.6\%) with IMRT. The incidences of RHT in patients who received neoadjuvant plus concurrent chemotherapy, only concurrent chemotherapy, and concurrent chemotherapy plus adjuvant chemotherapy were $19.44 \%$ (7 of 36 patients), 25.64\% (30 of 117 patients), and 50\% ( 1 of 2 patients). One of 19 patients who did not received chemotherapy experienced RHT (5.26\%). 


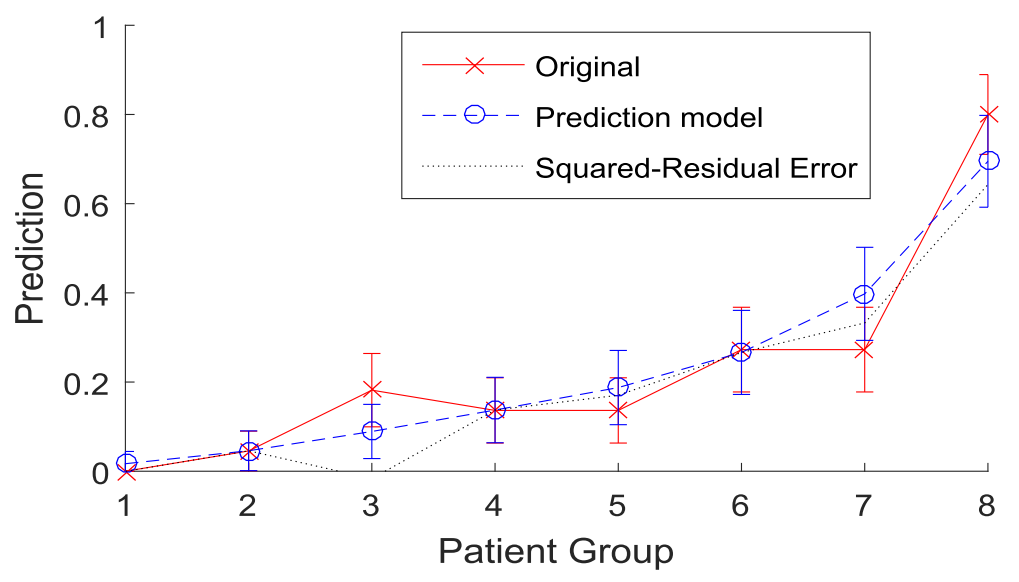

Fig. 2 The octile plot displays the goodness-of-fit of our NTCP model

Additional information about patient characteristics and treatment is shown in Table 2.

After a median follow-up of 24 (range, 3 to 66) months, biochemical HT occurred in 39 (22.4\%) patients. The mean values of $\mathrm{P}_{\text {mean }}$ and $\mathrm{P}_{\max }$ of pituitary gland were 30.366 (range, 2.758 to 72.274 ) Gy and 37. 856 (range, 3.735 to 74.070 ) Gy, respectively, but no patients were diagnosed as central HT. The estimated incidences of RHT were $14.4 \%, 22.4 \%$ and $24.9 \%$ at 12,18 and 24 months, respectively (Fig. 1). The median latency of biochemical HT was 9 (range, 3 to 48) months after radiotherapy and 37 (94.9\% of 39$)$ patients developed biochemical HT within 24 months.

The cross-correlation matrixes of parameters were showed in Additional file 1: Table S1. High correlations (correlation coefficient $>0.85$ ) were found between dosevolume factors but not in clinical factors. As a result, most of the dosimetric factors except $\mathrm{D}_{\max }, \mathrm{V}_{50}, \mathrm{~V}_{60}$, and $\mathrm{P}_{\max }$ were excluded from NTCP modeling process to avoid overfitting. Thus, only clinical factors and $D_{\max }$, $\mathrm{V}_{50}, \mathrm{~V}_{60}$, and $\mathrm{P}_{\max }$ were taken into the modeling process. At first, the model order was determined to be four by

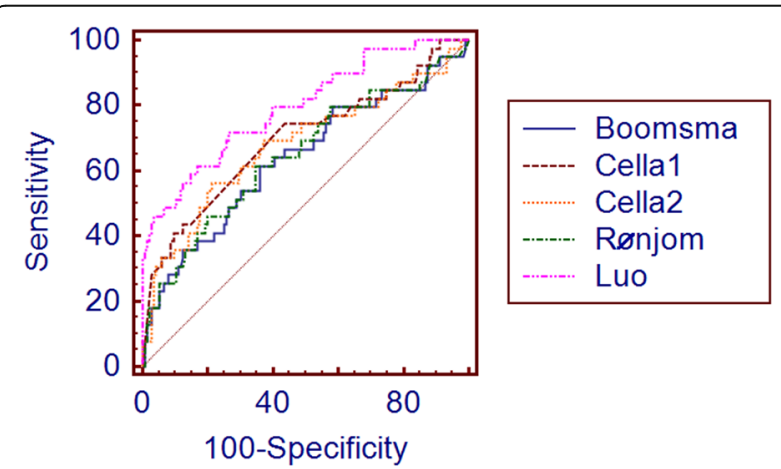

Fig. 3 Receiver operating characteristic curves (ROC) of five biochemical hypothyroidism NTCP models in NPC cohort leave-one-out cross-validation method. Subsequently, in model parameters estimation, gender, chemotherapy, $\mathrm{V}_{50}$, and $\mathrm{P}_{\max }$ of thyroid gland were identified as the optimal parameters of this four-variable NTCP model for biomedical HT (Table 1). The results of univariate and multivariate analysis of dosimetric variables are showed in Table 3. The Hosmer-Lemeshow test $(p=0.306)$ and the octile plot (Fig. 2) show goodness-of-fit of our NTCP model.

Because the AUC was unavailable in Rønjom et al.'s article [17], the AUCs of the rest four models in their corresponding patient cohort were compared. There was no significantly statistical difference between our NTCP model and the other three models (Table 4). AUCs of five models were calculated based on our NPC cohort. Compared to the other four AUCs, the AUC of Luo et al. model was statistically higher $[14,16,17]$ (Table 4). The receiver operating characteristic curves of the five models are depicted in Fig. 3.

\section{Discussion}

Hypothyroidism is a common side effect caused by radiotherapy in NPC patients. However, in China, thyroid function tests are not routine clinical practice neither before nor after radiotherapy for NPC patients. In this study, the incidence of biochemical HT after radiotherapy is 23.9\%, which is similar to other NPC studies $[3,4,6,12]$. We found the latency of biochemical HT is short (median 9 months) and most of the biochemical HT (89.7\%, 35 in 39 patients) developed within 18 months postradiotherapy. The previous studies also showed that the peak incidence of RHT was 1 to 2 years after radiotherapy $[10,14,15,25-27]$. The incidence of RHT will further increase within a longer follow-up period [28] and the patients with subclinical HT will develop clinical HT in the future follow-up [6]. Therefore, we suggest regular followup for thyroid function in the first two years postradiotherapy is particularly important and the further 
Table 4 Comparision of five models using AUC

\begin{tabular}{llllllll}
\hline & AUC* & $95 \% \mathrm{Cl}$ & $\mathrm{p}^{\ddagger}$ & $\mathrm{AUC}^{\dagger}$ & $95 \% \mathrm{Cl}$ & $\mathrm{p}^{\S}$ \\
\hline Boomsma & 0.85 & $0.78-0.92$ & 0.134 & 0.636 & $0.560-0.708$ & 0.022 & 0.008 \\
Cella model 1 & 0.865 & $0.793-0.945$ & 0.082 & 0.694 & $0.620-0.762$ & 0.001 & 0.030 \\
Cella model 2 & 0.874 & $0.750-0.951$ & 0.159 & 0.677 & $0.602-0.746$ & 0.003 \\
Rønjom & $\mathrm{NA}$ & $\mathrm{NA}$ & $\mathrm{NA}$ & 0.646 & $0.570-0.717$ & 0.014 & 0.024 \\
Luo & 0.793 & $0.725-0.851$ & & 0.793 & $0.725-0.851$ & 0.000 \\
\hline
\end{tabular}

$\mathrm{AUC}^{*}$, area under the receiver operating characteristic curve calculated in each own cohort

$\mathrm{AUC}^{\dagger}$, area under the receiver operating characteristic curve calculated in NPC cohort

$\mathrm{p}^{\ddagger}, \mathrm{p}$-value evaluated in each own cohort respect to Luo et al. model

$p^{\S}, p$-value of each $\mathrm{AUC}^{\dagger}$

$\mathrm{p}^{\natural}, \mathrm{p}$-value evaluated in NPC cohort respect to Luo et al. model

NA, not available

follow-up (even lifelong) thereafter is also necessary for the patients who received cervical radiation.

In accordance with the previous studies $[3,8,9,16,19$, $22]$, the female gender and $V_{50}$ were identified as risk factors in this study. It remains controversial $[9,29-31]$ whether chemotherapy is a predictor of RHT. However, in our previous study [22], chemotherapy plays a major role in the nomogram for biochemical HT prediction in NPC patients. In this study, only one experienced biochemical HT among 19 patients who did not receive chemotherapy, and chemotherapy was identified as an independent predictor in the multivariate analysis. The $\mathrm{P}_{\max }$ was found as a protective factor of biochemical HT, which might due to the radiation effect to the pituitary gland by preventing the TSH increasing [3].

Cella et al. [16] reported two NTCP models in Hodgkin's lymphoma patients respectively based on thyroid $\mathrm{V}_{30}$ plus gender, and $\mathrm{V}_{30} \mathrm{Cc}$, gender plus thyroid volume (Table 1). The initial thyroid volume and $\mathrm{D}_{\text {mean }}$ based NTCP models were built in two studies $[14,17]$ of nonNPC head and neck cancer patients (Table 1). In this study, we develop a NTCP model based on gender, chemotherapy, $\mathrm{V}_{50}$, and $\mathrm{P}_{\max }$. All these five studies used the same endpoint (biochemical HT) and uncorrected dosimetric parameters to construct the NTCP models, which made them comparable.

Firstly, when the model performance of the four models was evaluated in their respective cohorts, the difference between our NTCP model and the other three models was not significant. Secondly, the model performance of the five models was calculated and compared in our NPC cohort, and we found the performance of Luo et al. model was significantly better than the other four models $[14,16,17]$ that were derived from non-NPC patients. Models derived from different patient populations and the NPC patients being the external cohort for the other four models may result in decreasing performance in non-NPC models. However, a main difference from other models was that Luo et al. model included the dosimetric factor of pituitary which might help to improve the model performance in predicting biochemical HT in NPC patients. Therefore, considering the effect of radiation on both the pituitary and thyroid glands might be necessary for modeling NTCP model for RHT in NPC patients. The thyroid volume was not identified as a predictive factor in this study, which might be the possible reason for the relatively low performance of two NTCP models which were based on thyroid volume $[14,17]$ in this cohort.

Lo Galbo et al. [32] and Lin et al. [33] revealed that autoimmune response was correlated to RHT. To improve the performance of NTCP models for RHT, it is considerable to introduce thyroid autoimmune factors such as thyroperoxidase antibody and thyroglobulin antibody into the modeling process. In this regard, it may be rational to add these two immunologic tests to the regular follow-up for patients who received irradiation to the neck areas.

There were still some limitations to this study. The median follow-up (24 months) was relatively short, which may make a negative impact on estimating long-term risk on RHT with our NTCP model. In a recent study [6], pituitary dosimetric factors have been found not correlated with either biochemical or clinical HT. Thus, a prospective-designed study with longer follow-up period is necessary to validate the importance of the effect of irradiation on the pituitary gland and our NTCP model.

\section{Conclusions}

We have developed a four-variable NTCP model for RHT in NPC patients post-radiotherapy and demonstrated its high prediction capability.

\section{Additional file}

Additional file 1: Table S1. Spearman's rank self-correlation matrix of clinical and dosimetric variables. (XLS 26 kb)

\section{Abbreviations}

3D-CRT: 3-dimensional conformal radiotherapy; AJCC: American Joint Committee on Cancer; AUC: Area under the receiver operating characteristic curve; CTVnd: The lymph nodes of the clinical target volume; CTVnx: The 
clinical target volume of the nasopharynx; $D_{\text {max: }}$ The maximum dose; $D_{\text {mean }}$ : The thyroid mean dose; $D_{\text {min }}$ : The thyroid minimum dose; fT3: Serum free triiodothyronine; fT4: Serum free thyroxine; GTV: The gross tumor volume; GTVnd: The lymph nodes of the gross tumor volume; GTVnx: The primary disease of the gross tumor volume; HT: Hypothyroidism; IMRT: Intensity-modulated radiotherapy; NPC: Nasopharyngeal carcinoma; NTCP: Normal tissue complication probability; OARs: Organs at risk; $P_{\max }$ : The maximum dose of the pituitary; PTV: The planning target volume; RHT: Radiation-induced hypothyroidism; TPS: Treatment planning system; TSH: Serum thyroid-stimulating hormone; $V_{30} \mathrm{cc}$ : The absolute thyroid volume receiving more than $30 \mathrm{~Gy} ; V_{50}$ : The percentage thyroid volume receiving more than $50 \mathrm{~Gy} ; \mathrm{V}_{\mathrm{x}}$ : The percentage of thyroid volume receiving more than X Gy

\section{Availability of data and materials}

The datasets in this study are available from the corresponding author on reasonable request.

\section{Authors' contributions}

RL designed the research, analyzed the data and wrote the paper. WWW revised the paper and did language editing. BHH, XYG, ZXX, DDW collected data. ZNY collected data and edited the figures in proper format. ML and ZXL designed the research, wrote and revised the paper. All authors gave the final approval of the manuscript's submission.

\section{Ethics approval and consent to participate}

This study was approved by Medical Ethics Committee of Cancer Hospital of Shantou University Medical College and all patients signed written informed consent before the initiation of therapy.

\section{Competing interests}

The authors declare that they have no competing interests.

\section{Publisher's Note}

Springer Nature remains neutral with regard to jurisdictional claims in published maps and institutional affiliations.

\section{Author details}

${ }^{1}$ Department of Radiation Oncology, Cancer Hospital of Shantou University Medical College, 7 Raoping Road, Shantou 515000, Guangdong, China. ${ }^{2}$ Department of Radiation Oncology, Medical Center - University of Freiburg, Freiburg, Germany. ${ }^{3}$ Department of Health Technology and Informatics, Hong Kong Polytechnic University, Hong Kong, China.

\section{Received: 22 August 2017 Accepted: 8 April 2018}

\section{Published online: 18 May 2018}

\section{References}

1. Rønjom: Radiation-induced hypothyroidism after treatment of head and neck cancer. 2015

2. Lin ZX, Yang ZN, Zhan YZ, Xie WJ, Li GW, Feng HT. Application study of the 2008 staging system of nasopharyngeal carcinoma. Ai Zheng. 2009;28(10): 1029-32.

3. Wu YH, Wang HM, Chen HH, Lin $\mathrm{CY}$, Chen EY, Fan KH, Huang SF, Chen IH, Liao CT, Cheng AJ, et al. Hypothyroidism after radiotherapy for nasopharyngeal cancer patients. Int J Radiat Oncol Biol Phys. 2010; 76(4):1133-9.

4. Lin Z, Wu WW, Lin J, Feng H, Chen L. A longitudinal study on the radiationinduced thyroid gland changes after external beam radiotherapy of nasopharyngeal carcinoma. Thyroid. 2011;21(1):19-23.

5. Huang S, Wang X, Hu C, Ying H. Hypothalamic-pituitary-thyroid dysfunction induced by intensity-modulated radiotherapy (IMRT) for adult patients with nasopharyngeal carcinoma. Med Oncol. 2013;30(4):710.

6. Lee V, Chan SY, Choi CW, Kwong D, Lam KO, Tong CC, Sze CK, Ng S, Leung TW, Lee A. Dosimetric predictors of hypothyroidism after radical intensitymodulated radiation therapy for non-metastatic nasopharyngeal carcinoma. Clin Oncol. 2016;28(8)::52-60

7. Chua ML, Wee JT, Hui EP, Chan AT. Nasopharyngeal carcinoma. Lancet (London, England). 2016;387(10022):1012-24.

8. Alterio D, Jereczek-Fossa BA, Franchi B, D'Onofrio A, Piazzi V, Rondi E, Ciocca M, Gibelli B, Grosso E, Tradati N, et al. Thyroid disorders in patients treated with radiotherapy for head-and-neck cancer: a retrospective analysis of seventy-three patients. Int J Radiat Oncol Biol Phys. 2007;67(1):144-50.

9. Ling S, Bhatt AD, Brown NV, Nguyen P, Sipos JA, Chakravarti A, Rong Y. Correlative study of dose to thyroid and incidence of subsequent dysfunction after head and neck radiation. Head Neck. 2017;39(3):548-54.

10. Murthy V, Narang K, Ghosh-Laskar S, Gupta T, Budrukkar A, Agrawal JP. Hypothyroidism after 3-dimensional conformal radiotherapy and intensitymodulated radiotherapy for head and neck cancers: prospective data from 2 randomized controlled trials. Head Neck. 2014;36(11):1573-80.

11. Sommat K, Ong WS, Hussain A, Soong YL, Tan T, Wee J, Fong KW: Thyroid V40 Predicts Primary Hypothyroidism Following Intensity Modulated Radiotherapy for Nasopharyngeal Carcinoma. International Journal of Radiation Oncology • Biology • Physics (in Press).

12. Zhai RP, Kong FF, Du CR, Hu CS, Ying HM. Radiation-induced hypothyroidism after IMRT for nasopharyngeal carcinoma: clinical and dosimetric predictors in a prospective cohort study. Oral Oncol. 2017; 68:44-9.

13. Grande C. Hypothyroidism following radiotherapy for head and neck cancer: multivariate analysis of risk factors. Radiother Oncol. 1992;25(1):31-6.

14. Boomsma MJ, Bijl HP, Christianen ME, Beetz I, Chouvalova O, Steenbakkers RJ, van der Laan BF, Wolffenbuttel BH, Oosting SF, Schilstra C, et al. A prospective cohort study on radiation-induced hypothyroidism: development of an NTCP model. Int J Radiat Oncol Biol Phys. 2012;84(3):e351-6.

15. Cella L, Conson M, Caterino M, De Rosa N, Liuzzi R, Picardi M, Grimaldi F, Solla R, Farella A, Salvatore M, et al. Thyroid V30 predicts radiation-induced hypothyroidism in patients treated with sequential chemo-radiotherapy for Hodgkin's lymphoma. Int J Radiat Oncol Biol Phys. 2012;82(5):1802-8.

16. Cella L, Liuzzi R, Conson M, D'Avino V, Salvatore M, Pacelli R. Development of multivariate NTCP models for radiation-induced hypothyroidism: a comparative analysis. Radiat Oncol. 2012;7:224.

17. Ronjom MF, Brink C, Bentzen SM, Hegedus L, Overgaard J, Johansen J. Hypothyroidism after primary radiotherapy for head and neck squamous cell carcinoma: normal tissue complication probability modeling with latent time correction. Radiother Oncol. 2013;109(2):317-22.

18. Kim MY, Yu T, Wu HG. Dose-volumetric parameters for predicting hypothyroidism after radiotherapy for head and neck Cancer. Jpn J Clin Oncol. 2014:44(4):331-7.

19. Sachdev S, Refaat T, Bacchus ID, Sathiaseelan V, Mittal BB. Thyroid V50 highly predictive of hypothyroidism in head-and-neck cancer patients treated with intensity-modulated radiotherapy (IMRT). Am J Clin Oncol. 2014. [Epub ahead of print].

20. Fujiwara M, Kamikonya N, Odawara S, Suzuki H, Niwa Y, Takada Y, Doi H, Terada T, Uwa N, Sagawa K, et al. The threshold of hypothyroidism after radiation therapy for head and neck cancer: a retrospective analysis of 116 cases. J Radiat Res. 2015;56(3):577-82.

21. El Naqa I, Bradley J, Blanco Al, Lindsay PE, Vicic M, Hope A, Deasy JO. Multivariable modeling of radiotherapy outcomes, including dose-volume and clinical factors. Int J Radiat Oncol Biol Phys. 2006;64(4):1275-86.

22. Luo R, Li M, Yang Z, Zhan Y, Huang B, Lu J, Xu Z, Lin Z. Nomogram for radiation-induced hypothyroidism prediction in nasopharyngeal carcinoma after treatment. Br J Radiol. 2016;90(1070):20160686.

23. Lee N, Harris J, Garden AS, Straube W, Glisson B, Xia P, Bosch W, Morrison WH, Quivey J, Thorstad W, et al. Intensity-modulated radiation therapy with or without chemotherapy for nasopharyngeal carcinoma: radiation therapy oncology group phase II trial 0225. J Clin Oncol. 2009;27(22):3684-90.

24. DeLong ER, DeLong DM, Clarke-Pearson DL. Comparing the areas under two or more correlated receiver operating characteristic curves: a nonparametric approach. Biometrics. 1988;44(3):837-45.

25. Chyan A, Chen J, Shugard E, Lambert L, Quivey JM, Yom SS. Dosimetric predictors of hypothyroidism in oropharyngeal cancer patients treated with intensity-modulated radiation therapy. Radiat Oncol. 2014;9:269.

26. Akgun Z, Atasoy BM, Ozen Z, Yavuz D, Gulluoglu B, Sengoz M, Abacioglu U. V30 as a predictor for radiation-induced hypothyroidism: a dosimetric analysis in patients who received radiotherapy to the neck. Radiat Oncol. 2014;9:104.

27. Diaz R, Jaboin JJ, Morales-Paliza M, Koehler E, Phillips JG, Stinson S, Gilbert J, Chung CH, Murphy BA, Yarbrough WG, et al. Hypothyroidism as a consequence of intensity-modulated radiotherapy with concurrent taxanebased chemotherapy for locally advanced head-and-neck cancer. Int J Radiat Oncol Biol Phys. 2010;77(2):468-76. 
28. Boomsma MJ, Bij HP, Langendijk JA. Radiation-induced hypothyroidism in head and neck cancer patients: a systematic review. Radiother Oncol. 2011; 99(1):1-5.

29. Hancock SL, Cox RS, McDougall IR. Thyroid diseases after treatment of Hodgkin's disease. N Engl J Med. 1991;325(9):599-605.

30. Norris AA, Amdur RJ, Morris CG, Mendenhall WM. Hypothyroidism when the thyroid is included only in the low neck field during head and neck radiotherapy. Am J Clin Oncol. 2006;29(5):442-5.

31. Bhandare N, Kennedy L, Malyapa RS, Morris CG, Mendenhall WM. Primary and central hypothyroidism after radiotherapy for head-and-neck tumors. Int J Radiat Oncol Biol Phys. 2007:68(4):1131-9.

32. Lo Galbo AM, de Bree R, Kuik DJ, Lips PT, Mary B, Von Blomberg E, Langendijk JA, Leemans CR. The prevalence of hypothyroidism after treatment for laryngeal and hypopharyngeal carcinomas: are autoantibodies of influence? Acta Otolaryngol. 2007:127(3):312-7.

33. Lin Z, Chen L, Fang Y, Cai A, Zhang T, Wu VWC. Longitudinal study on the correlations of thyroid antibody and thyroid hormone levels after radiotherapy in patients with nasopharyngeal carcinoma with radiationinduced hypothyroidism. Head Neck. 2014;36(2):171-5.

Ready to submit your research? Choose BMC and benefit from:

- fast, convenient online submission

- thorough peer review by experienced researchers in your field

- rapid publication on acceptance

- support for research data, including large and complex data types

- gold Open Access which fosters wider collaboration and increased citations

- maximum visibility for your research: over $100 \mathrm{M}$ website views per year

At BMC, research is always in progress.

Learn more biomedcentral.com/submissions 